\title{
Energy, Carbon and Cost Performance of Building Stocks: Upgrade Analysis, Energy Labelling and National Policy Development
}

\author{
Clarke J A, Johnstone C M, Kim J M and Tuohy P G \\ Energy Systems Research Unit \\ University of Strathclyde \\ esru@strath.ac.uk
}

Keywords: national building stock, performance simulation, upgrade policy, energy performance certificate.

\begin{abstract}
The area of policy formulation for the energy and carbon performance of buildings is coming under increasing focus. A major challenge is to account for the large variation within building stocks relative to factors such as location, climate, age, construction, previous upgrades, appliance usage, and type of heating/cooling/lighting system. Existing policy-related tools that rely on simple calculation methods have limited ability to represent the dynamic interconnectedness of technology options and the impact of possible future changes in climate and occupant behaviour. The use of detailed simulation tools to address these limitations in the context of policy development has hitherto been focussed on the modelling of a number of representative designs rather than dealing with the spread inherent in large building stocks. Further, these tools have been research-oriented and largely unsuitable for direct use by policy-makers, practitioners and, ultimately, building owners/occupiers.

This paper summarises recent initiatives that have applied advanced modelling and simulation in the context of policy formulation for large building stocks. To exemplify the stages of the process, aspects of the ESRU Domestic Energy Model (EDEM) are described. EDEM is a policy support tool built on detailed simulation models aligned with the outcomes of national surveys and future projections for the housing stock. On the basis of pragmatic inputs, the tool is able to determine energy use, carbon emissions and upgrade/running cost for any national building stock or sub-set. The tool has been used at the behest of the Scottish Building Standards Agency and South Ayrshire Council to determine the impact of housing upgrades, including the deployment of new and renewable energy systems, and to rate the energy/carbon performance of individual dwellings as required by the European Commission's Directive on the Energy Performance of Buildings (EC 2002).
\end{abstract}

\section{Introduction}

An essential element in promoting the rational use of energy is that decision-makers be given access to relevant sources of information. These include energy demand profiles and characteristics of potential sources of supply; and the outputs from studies to assess the impact of possible alternative strategies. However, indications are that at present comprehensive information is rarely in the hands of those who require it and the use of 
modelling in strategy formulation is virtually unknown. This paper describes projects that imply an attempt to change this situation.

The worldwide building stock (residential and commercial) is responsible for over 33\% of global $\mathrm{CO}_{2}$ emissions (de la Rue du Can and Price, 2008), and a large mitigation potential has been identified (Urge-Vorsatz and Novikova, 2008). To attain aspirational $\mathrm{CO}_{2}$ reduction targets, such as the EU's $20 \%$ reduction by 2020 or the UK's $60 \%$ reduction by 2050, will require the implementation of radical construction upgrades, new technology deployments and, contentiously, lifestyle change.

The simplified energy/carbon calculators presently in use, such as defined in CEN Standard 13790 (ISO, 2007) or the UK's Standard Assessment Procedure (BRE, 2005), are based on energy balance methods that do not account fully for the inherently interactive and dynamic characteristics of buildings; Figure 1 contrasts graphically the energy balance underlying a simplified and simulation based approach. Such methods cannot adequately represent the performance of the myriad upgrade options that may be applied individually or in combination. Also, as buildings have extended lifetimes, it is important to assess performance under likely future contexts, such as occupant behavioural change, climate change and the emergence of new technologies.

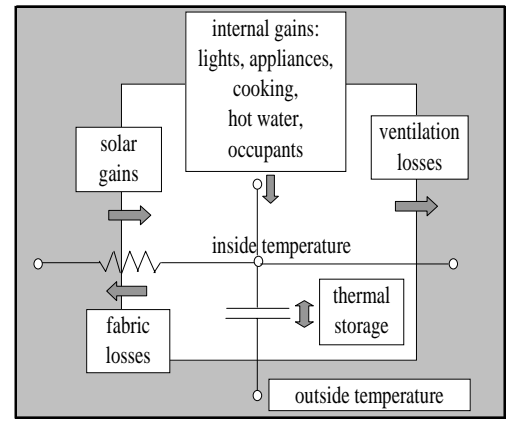

a) simplified

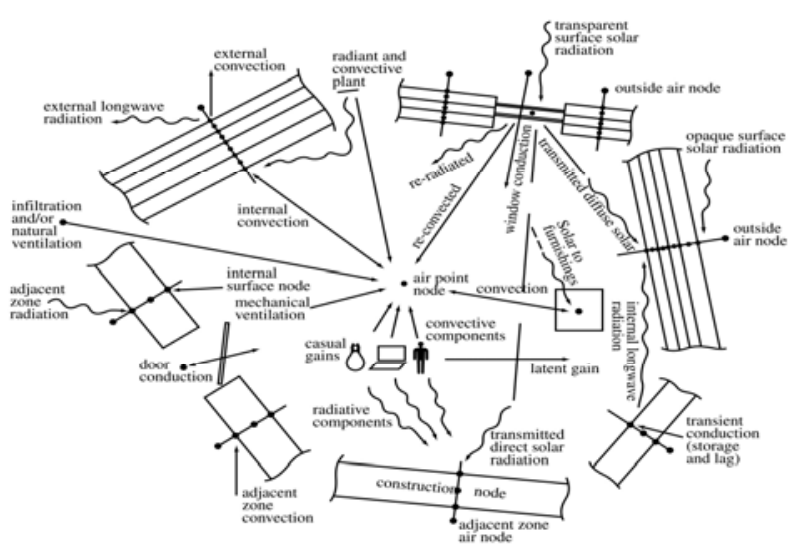

b) simulation-based

Figure 1: Visual comparison of simple and simulation-based room energy models.

There are many available building simulation tools (Crawley et al, 2008) and these offer considerable advantages over their simplified counterparts, particularly in the areas of dynamic building response, adaptive occupant comfort, ventilation, indoor air quality, novel control and renewable energy systems integration. The simulation approach is increasingly being mandated in building performance legislation and applied in studies to inform policy.

Crawley (2007, 2007a) reported on a simulation-based study to assess the impact of climate change and urban heat island effects on future building performance. A method was developed and applied to generate future weather collections for 25 locations in 20 
climate zones around the world. This resulted in 525 weather collections encapsulating recent urban heat island data and the 4 economic scenarios and general climate assumptions of the Intergovernmental Panel on Climate Change. The intention is to use these collections to establish future climate impacts for a range of building types after various energy performance enhancements have been applied. To date, a model representing $25 \%$ of the US office stock has been simulated for US locations, with three levels of enhancement applied corresponding to current practice, best practice and future practice scenarios. The results give the impact on heating and cooling energy use for combinations of location, climate change and selected efficiency measures.

Heiple and Sailor (2008) investigated energy supply and heat island effects by simulating building energy use at the urban scale. Their approach employed prototypical models representing 8 dwelling and 22 non-dwelling types. Entire districts were then mapped to these models using Geographical Information System (GIS) techniques and simple surveys. The energy use predictions were then communicated to policy-makers via GIS overlays. The researchers reported agreement with utility data to within $10 \%$.

Research at Osaka University characterised urban energy performance via the use of simulation models that include stochastic algorithms to represent variations in usage patterns. The method was initially demonstrated for two large offices supplied by cogeneration plant and absorption chillers (Yamaguchi et al, 2003). A second study (Hashimoto et al, 2007) focussed on two office districts of different density and investigated various energy supply solutions (e.g. district heating/cooling and water/air source heat pumps). A third study (Taniguchi et al, 2007) investigated residential energy use. Models were constructed corresponding to 228 residential categories differentiated by family and building type and 5 insulation levels based on property age. The residential sectors of 20 Japanese cities were then mapped to these categories and the models, after calibration by comparison with utility data, used to investigate the efficacy of energy efficiency measures, including reduced appliance use based on Japan's 'top-runner' policy, increased insulation, improved air conditioner efficiency, and modified temperature set-points.

In the UK, the Carbon Vision project (Carbon Trust, 2008) set out to provide the strategy and evidence base to allow the UK to meet its $60 \%$ carbon reduction goal by 2050 . The 'Technology Assessment for Radically Improving the Built Asset Base' (TARBASE) sub-project carried out dynamic simulation modelling for representative building types in order to determine the applicability and likely impact of specific upgrade measures. Preliminary results indicate that a $70 \%$ reduction in emission is possible at a cost of between $£ 7,000$ and $£ 21,000$ for the selected dwellings (Staunton, 2008).

A number of simulation-based policy studies have been undertaken in China. Li et al (2007) proposed a method to investigate building upgrade scenarios for housing in Xi'an City, with results displayed on GIS maps. Hu et al (2007) carried out a study of upgrade options based on apartments in a typical multi-dwelling building. Xie et al (2007) evaluated office cooling loads for three different cities in Hunan province. 
Studies such as those above have generally set out to answer specific policy questions, with the tools developed and applied by building performance researchers in order to explore policy implications. In contrast, some recent projects in the UK have set out to develop tools for direct use by policy-makers.

Jones et al (2001) developed the Energy and Environmental Prediction (EEP) planning support tool, which is able to quantify energy use and associated emissions for cities and regions. EEP is based on GIS techniques, with representative models for the building, industry and transport sectors. The tool has been applied to the Neath Port Talbot County Borough comprising 60,000 dwellings and 4,000 commercial properties. Figure 2, for example, shows a typical outcome from a cost-performance assessment of houses at the district level.

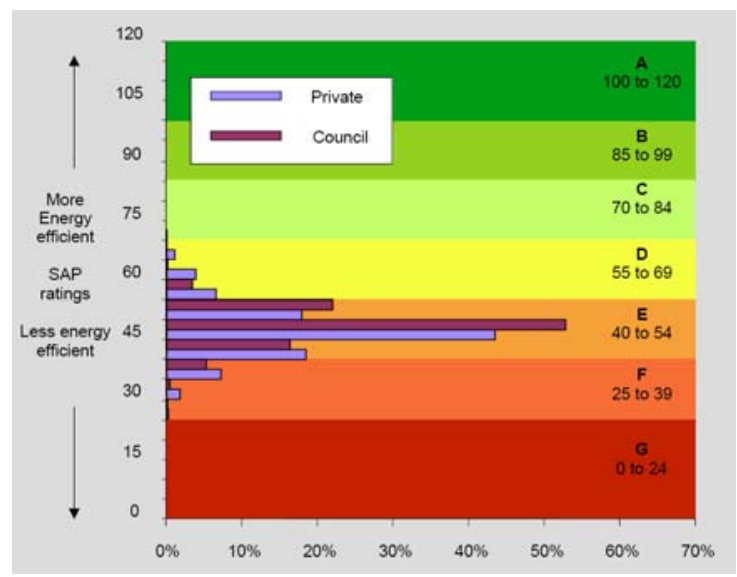

a) Percentage of homes having SAP ratings in the indicated ranges.

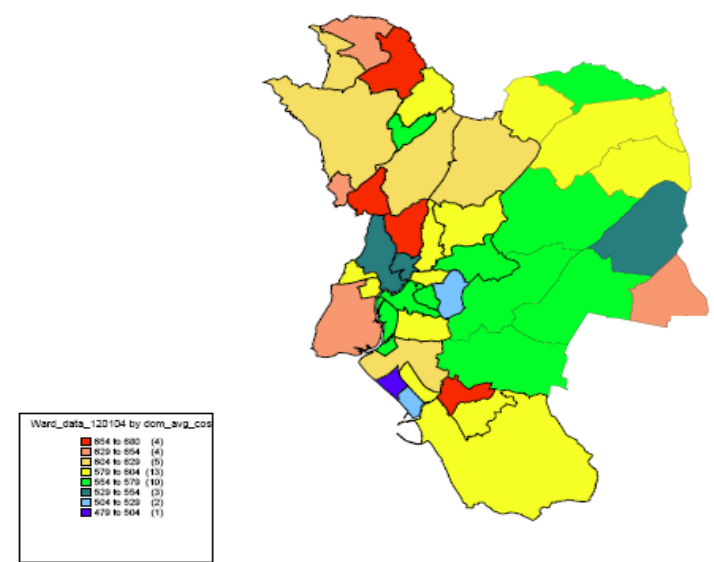

b) Average domestic heating cost per ward.

Figure 2: Example of home energy/cost rating using the EEP system.

The EnTrak system (Clarke et al, 1997; Kim and Clarke, 2004) enables the tracking of regional/city energy use over time, with a range of interrogations provided to support energy action planning. Embedded simulation models are used to augment sparse data sets and to quantify the impact of upgrades or the deployment of renewable energy systems both locally and nationally. Figure 3 presents two example outputs: a) corresponds to a CHP feasibility study and presents heat-to-power ratios on a street-bystreet basis when classified into excellent, good, fair, poor and bad; b) corresponds to wind farm development control in Caithness, Scotland (Bamborough et al, 1996) with the two GIS maps representing policy and technical ratings to a $1 \mathrm{~km}^{2}$ resolution using appropriate scoring criteria. In the latter case a comparison shows that policy rather than technical issues are likely to be the constraint on wind farm development within the region.

Clarke et al (2004) have developed the ESRU Domestic Energy Model (EDEM, 2007) as a generalised housing stock modeller, which encapsulates the results of simulations together with financial information to predict the energy, carbon and economic 
implications of stock upgrading over time. As a result of its simulation basis, EDEM is equipped to analyse all possible future upgrade options, while taking into account issues such as climate change and user behaviour adaptation.

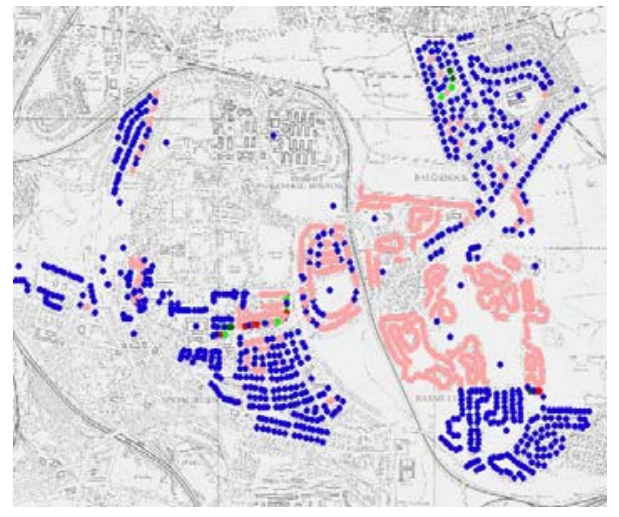

a) city CHP feasibility study
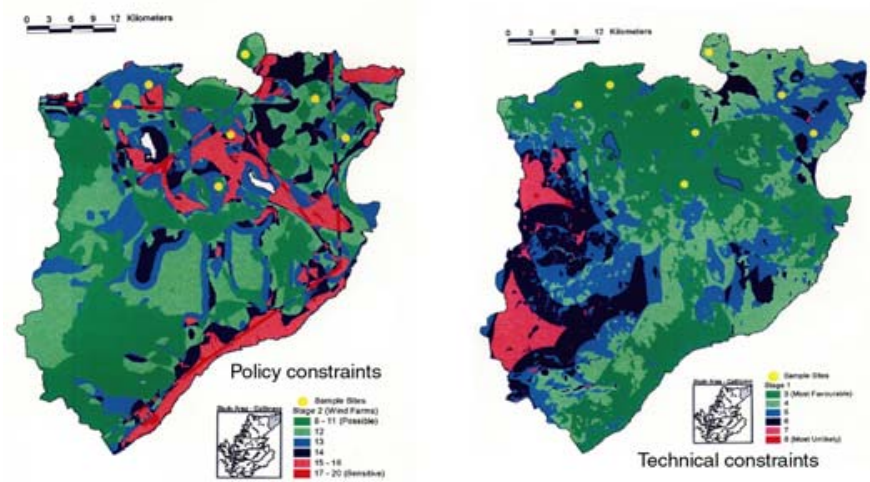

b) policy/technical rating of wind farm proposals

Figure 3: Example analyses using the EnTrak system.

\section{Building stock description}

All the above approaches depend on a sound knowledge of the building stock to be analysed and, although complex, this can usually be gleaned from national housing surveys, building regulation change histories, landlord property inventories, maintenance records and/or site surveys.

In Scotland, for example, there are around 2,278,000 dwellings of which $4 \%$ are vacant and $2.5 \%$ are due for demolition. The majority of dwellings are either houses $(62 \%)$ or flats (38\%). Over $40 \%$ of all dwellings were built within the last 37 years, with $24 \%$ constructed between 1945 and 1965. The 2002 Scottish House Condition Survey (Scottish Homes, 2002) identified 7 predominant house types (Detached, Semi-detached, Terraced, Tenement Flat, Four-in-a-Block, Conversion and Tower/Slab Block) and established a mean National Home Energy Rating (NHER) of 4.5 (on a scale of 0/poor to 10/good), with an associated mean Standard Assessment Procedure (SAP) rating of 46.5 (on a scale of 0/poor to 100/good). $\mathrm{CO}_{2}$ emissions were estimated at 16.2 million tonnes per year. By comparison, the 1996 Scottish House Condition Survey identified a mean NHER rating of 4.1 and a mean SAP rating of 43, indicating a $10 \%$ improvement over the intervening period, with $12 \%$ of all dwellings achieving an NHER rating between 7 and 9 and no dwellings attaining a rating of 10 .

From the 2002 survey, around 86\% of dwellings were identified as having whole house central heating, with a further $8 \%$ having partial central heating. This represents a $6 \%$ improvement since 1996, with the number of dwellings with no central heating down from $13 \%$ to $5.5 \%$. This small but significant figure gives rise to concerns about fuel poverty and the related health problems associated with hypothermia, condensation and mould growth. Although around $90 \%$ of houses have loft insulation, in only $27 \%$ of cases does this meet or surpass the 1991 building standard. In the Scottish context therefore, the 
need for housing stock improvement is palpable: this need is likely to be echoed in many countries throughout the world.

\section{Stock modelling approach}

While it is a straightforward task to identify house types from an architecture and construction viewpoint (hereinafter referred to as an AC type), the task becomes semiintractable when viewed thermodynamically. Setting aside the effect of occupant behaviour, two separate houses, each belonging to the same AC type, may have substantially different energy consumption patterns as a result of dissimilar energy efficiency measures having been previously applied Likewise, two houses corresponding to different AC types may have the same normalised energy consumption because the governing thermodynamic-related design parameters are essentially the same.

One approach to stock modelling is to establish prototype models for each AC type and to then apply design parameter variations to each model to represent all possible upgrade combinations, while accepting that many of the permutations to result will give rise to identical performance outcomes. Another approach, and the one adopted within the EDEM tool, is to operate in terms of unique thermodynamic classes (TC) so that different AC types may belong to the same TC. A representative model may then be formed for each TC and its energy performance determined by simulation using real, representative weather data. Any actual house may then be related to a TC via the present level of its governing design parameters. Should any of these parameters be changed as part of an upgrade then that house would be deemed to have moved to another TC.

The simulation results for the set of representative TC models, scaled by the appropriate factors representing their proportion of the overall population, then define the possible performance of the entire housing stock, present and future, for the climate, exposure, occupancy and system control assumptions made within the simulations. By varying these assumptions and re-simulating, scenarios such as future climate change and improved living standard may be readily incorporated.

Within the EDEM project, the ESP-r system (ESP-r, 2007) was used to determine dwelling performance by subjecting the TC models to long term weather sequences that typify the range of possibilities for the region in question. The time series performance predictions for all TC models, when re-expressed as regression equations defining energy use as a function of prevailing weather parameters, are then encapsulated within the EDEM tool for use by relevant user groups: policy-makers engaged in the development of building regulations in response to national policy drivers; building stock owners/managers to appraise the impact of candidate improvement measures; and local authorities in a performance rating context.

The evaluation of any given upgrading scenario is quantified by assigning the dwellings in question to a TC based on principal design parameters. The energy reduction brought about by relocation to another TC may then be simply 'read off' as depicted in Figure 4, which shows the main EDEM control screen (see later). Because each TC corresponds to a unique design parameter combination, the required upgrade is immediately apparent from the TC relocation. The impact of technologies that may be considered independent of house type, such as district heating or community combined heat and power, are then modelled separately based on dwelling energy demands. Specific upgrade scenarios are 
accepted or discarded as a consequence of the resulting performance benefit and cost. The calculation of the domestic energy rating band and associated indexes as defined within the regulatory standards, are output for both the unimproved and improved case.

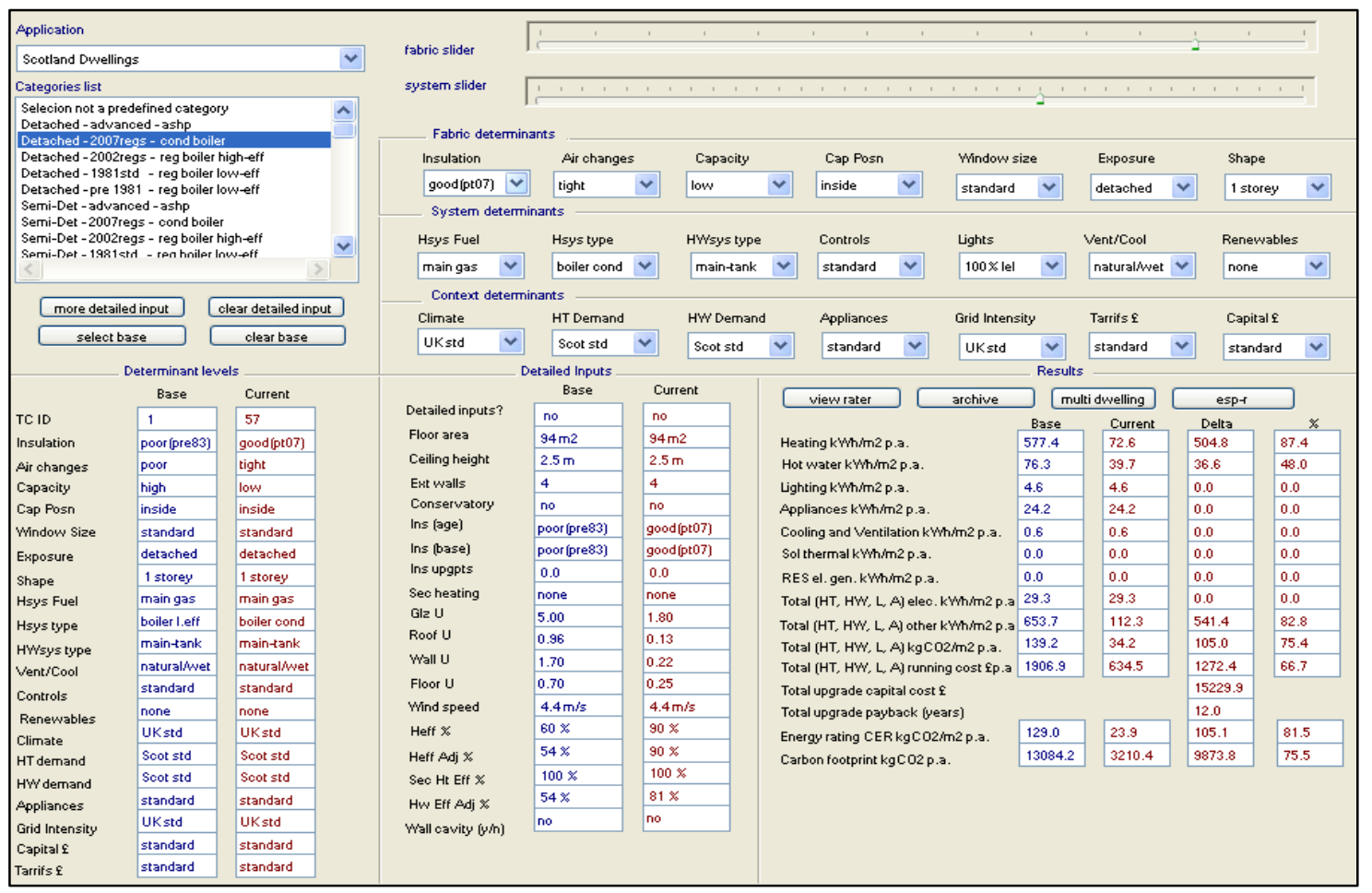

Figure 4: EDEM control screen.

By ensuring that the TC models encapsulate the assumptions underpinning the regulatory simplified calculation methods presently used for energy ratings (e.g. SAP in the UK), EDEM can be used in emulation mode when applied to the restricted cases for which these regulatory tools are valid.

\section{TC formulation}

TC models cover construction and technology related design parameters to allow an impact assessment of deploying different construction/technology upgrade combinations over time.

\subsection{Construction aspects}

The range of TC models to be processed are established as unique combinations of design parameters that may be considered as the main determinants of energy use and can be adjusted as part of any upgrade: insulation (6 levels), thermal capacity (2 levels), capacity position (3 levels), air permeability (3 levels), window size (3 levels), exposure (5 levels) and wall-to-floor ratio (2 levels). If each of these parameters can exist at the level indicated in parentheses then there will be 3,240 (6 $\times 2 \times 3 \times 3 \times 3 \times 5 \times 2)$ TC models representing the universe of possibilities. That is, any dwelling, existing or planned, will correspond to a unique combination of these parameters and therefore belong to one, and only one, TC. Significantly, most TC models will not correspond to existing dwellings 
because the stock presently comprises designs that may be regarded as poor in terms of energy use and carbon footprint. Rather, the majority represent future possibilities that will result from the application of upgrades.

Long term ESP-r simulations were conducted for the 3,240 TC models and the predicted energy demands normalised by floor area to render the results independent of dwelling size and so facilitate inter-comparison. The models were then re-simulated for each of 24 context combinations relating to climate (2), occupancy (2), temperature set-point (3) and appliance efficiency (2).

To facilitate the simulations, a standard house model was constructed comprising living, eating and sleeping areas, with appropriate parametric modifications applied to realise the individual TCs. While the assumptions underlying this standard model correspond to the UK situation as determined from appropriate publications (Bartholomew and Robinson, 1998; BRE, 2005; CIBSE, 2006; Scottish Homes, 2002; Shorrock and Utley, 2003), these can be readily changed to reflect any other situation.

\subsection{Technology aspects}

Dwelling energy demands, as extracted from the TC model simulations, are applied to technology models corresponding to the range of possible environmental control systems.

For heating/cooling systems, type, age, control and fuel type are used to set an efficiency value in line with CIBSE and SAP defaults (BRE, 2005), the BRE Domestic Energy Fact File (Shorrock and Utley, 2003) and the Carbon Trust's Building Market Transformation project database (MTP, 2006). Hot water loads are determined in relation to standard domestic system capacities and water usage rates (BRE, 2005), while lighting energy use is calculated using a standard model. New and renewable energy systems are also selectable: currently mono-/poly-crystalline and amorphous photovoltaic components, micro wind turbines, solar thermal collectors, air/ground source heat pumps, heat recovery ventilation, and combined heat and power.

A number of user-replaceable defaults are set within the tool: the default mapping of energy use to $\mathrm{CO}_{2}$ emission is based on data published by the UK Carbon Trust $(0.42$ $\mathrm{kg} / \mathrm{kWh}$ for grid electricity and $0.19 \mathrm{~kg} / \mathrm{kWh}$ for gas); fuel unit costs and standing charges values are based on the standards set for UK SAP; and the capital cost of construction and technology upgrades are based on current market information.

\section{EDEM verification}

Detailed models of 5 actual houses were subjected to simulation, energy efficiency improvements applied and the simulations re-run. The houses and their variants were then related to TCs based on the level of their principal design parameters. The predicted heating energy demands resulting from the detailed simulations were then compared to the value associated with the matched TC model. The results indicated disagreements averaging around $5 \%$ ( $3 \%$ to $-13 \%$ range), indicating that the TC approach is a reasonable proxy for the real situation.

A second study compared EDEM output with energy performance as determined using the UK NHER methodology. A Local Authority Energy Officer carried out detailed 
surveys of dwellings with electric and gas heating systems and computed their energy performance using the NHER Surveyor tool (NHER, 2008). EDEM was used to calculate carbon and energy performance data and the results compared to those from NHER; Figure 5 shows the agreement obtained.

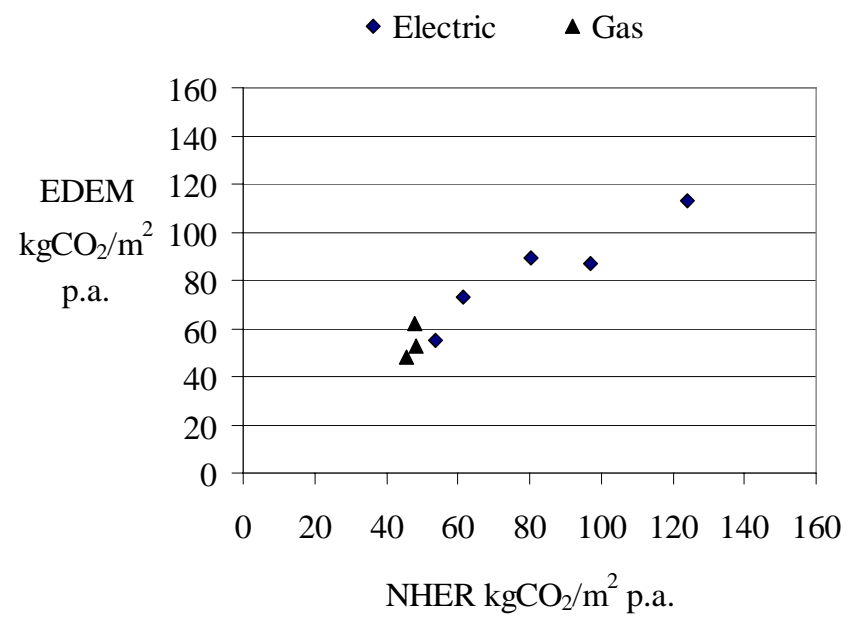

Figure 5: EDEM versus NHER Surveyor - CO2 emissions for dwellings with gas or electric heating systems.

\section{EDEM application}

EDEM is designed to be flexible in its application. The control screen (Figure 4) enables analysis at scales of integration from individual dwellings to entire housing stocks, with input data accepted at various levels of detail. The tool is configured to allow user customisation of the control screen labels, drop-down menus and data tables. A powerful scripting language is used to adapt the underlying models and contexts, to re-run simulations and to extract new values for the associated data tables. Alternative values for cost, carbon and system parameters can be directly entered.

\begin{tabular}{|c|c|c|c|c|c|c|c|c|c|c|c|c|}
\hline \multicolumn{13}{|c|}{ — Fabric deteminants } \\
\hline Insulation & \multicolumn{2}{|l|}{ Air changes } & \multicolumn{2}{|c|}{ Capacity } & \multicolumn{2}{|l|}{ Cap Posn } & \multicolumn{2}{|c|}{ Window size } & \multicolumn{2}{|l|}{ Exposure } & \multicolumn{2}{|l|}{ Shape } \\
\hline $\operatorname{good}(\mathrm{pt} 07) \vee v$ & tight & $v$ & low & $\checkmark$ & inside & $\checkmark$ & standard & $\vee$ & detached & $\checkmark$ & 1 storey & $v$ \\
\hline \multicolumn{13}{|c|}{ - System deteminants } \\
\hline Hsys Fuel & \multicolumn{2}{|l|}{ Hsys type } & \multicolumn{2}{|c|}{ HWsys type } & \multicolumn{2}{|l|}{ Controls } & \multicolumn{2}{|l|}{ Lights } & \multicolumn{2}{|l|}{ Venticool } & \multicolumn{2}{|c|}{ Renewables } \\
\hline main gas $v$ & boiler cond & $v$ & maintar & $v$ & standard & $v$ & $100 \%$ lel & $\checkmark$ & naturaliwe & $v$ & none & $\checkmark$ \\
\hline \multicolumn{13}{|c|}{ - Context deteminants } \\
\hline Climate & \multicolumn{2}{|l|}{ HT Demand } & \multicolumn{2}{|c|}{ HW Demand } & \multicolumn{2}{|l|}{ Appliances } & \multicolumn{2}{|c|}{ Grid Intensity } & \multicolumn{2}{|l|}{ Tarrifs \& } & \multicolumn{2}{|l|}{ Capital } \\
\hline UKstd & Scot std & 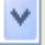 & Scot std & $v$ & standard & $\checkmark$ & UKstd & $v$ & standard & $\checkmark$ & standard & $v$ \\
\hline
\end{tabular}

Figure 6: Selection of input parameter levels in EDEM.

Once the context is defined and pragmatic input data gathered, construction- and technology-related parameters may be selected either directly (Figure 6) or by pre- 
defined category (Figure 7), and the outputs expressed in terms of energy/carbon/cost (Figure 8) and an Energy Performance Certificate (Figure 9). Improvements in construction- and technology-related parameters may then be evaluated by selecting parameters as above or by using sliders to rapidly evaluate upgrade options.

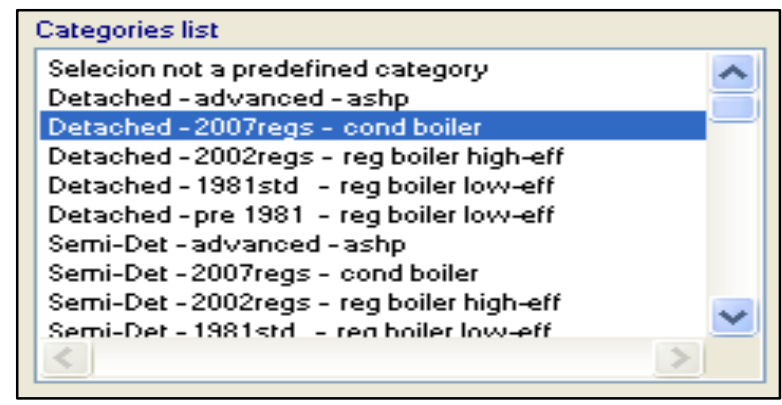

Figure 7: EDEM user configurable pre-defined categories provide a short-cut input data entry method for frequently used building types.

\begin{tabular}{|c|c|c|c|c|}
\hline \multirow{3}{*}{$\begin{array}{l}\text { Heating k'Whim2 p.a. } \\
\text { Hot water k'Wh/m2 p.a. }\end{array}$} & Base & Current & Delta & 必 \\
\hline & 577.4 & 72.6 & 504.8 & 87.4 \\
\hline & 76.3 & 39.7 & 36.6 & 48.0 \\
\hline \multirow{4}{*}{$\begin{array}{l}\text { Lighting k'Wh/m2 p.a. } \\
\text { Appliances k'Wh/m2 p.a. } \\
\text { Cooling and Wentilation k'Wh/m2 p.a. } \\
\text { Sol thermal k'Whim2 p.a. }\end{array}$} & 4.6 & 4.6 & 0.0 & 0.0 \\
\hline & 24.2 & 24.2 & 0.0 & 0.0 \\
\hline & 0.6 & 0.6 & 0.0 & 0.0 \\
\hline & 0.0 & 0.0 & 0.0 & 0.0 \\
\hline \multirow{2}{*}{$\begin{array}{l}\text { REs el. gen. kWhim2 p.a. } \\
\text { Total (HT, HW, L, A] elec. k'Whim2 p.a }\end{array}$} & 0.0 & 0.0 & 0.0 & 0.0 \\
\hline & 29.3 & 29.3 & 0.0 & 0.0 \\
\hline \multirow{3}{*}{$\begin{array}{l}\text { Total (HT, H'W, L, A) other k'Whim2 p.a } \\
\text { Total (HT, H'W, L, A) kgC02/m2 p.a. } \\
\text { Total (HT, H'W, L, A] running cost sp.a }\end{array}$} & 653.7 & 112.3 & 541.4 & 82.8 \\
\hline & 139.2 & 34.2 & 105.0 & 75.4 \\
\hline & 1906.9 & 634.5 & 1272.4 & 66.7 \\
\hline \multicolumn{3}{|l|}{ Total upgrade capital cost $\varepsilon$} & 15229.9 & \\
\hline \multicolumn{3}{|l|}{ Total upgrade payback [years] } & 12.0 & \\
\hline \multirow{2}{*}{$\begin{array}{l}\text { Energy rating CER kgC } 02 / m 2 \text { p.a. } \\
\text { Carbon footprint } \mathrm{kgCO} 2 \text { p.a. }\end{array}$} & 129.0 & 23.9 & 105.1 & 81.5 \\
\hline & 13084.2 & 3210.4 & 9873.8 & 75.5 \\
\hline
\end{tabular}

Figure 8: EDEM results summary illustrating a case where poor fabric and heating systems are upgraded to current standards.

An application will typically proceed as follows. The context of the analysis is set, e.g. 'current UK standard', '2050 climate with high indoor comfort' or '2050 climate with low carbon intensity electricity grid', and then for each dwelling type to be analysed the construction and technology input data are entered. The governing design parameters are then inferred from these data and the corresponding TC model automatically selected. The energy demand for the given model is then determined from the embedded database, adjusted for building specifics, and the delivered energy and associated costs and carbon emissions established. Upgrades of interest are then applied, resulting in a new TC model for processing to give new energy, carbon and financial results. Finally, combinations of interest are saved for comparison and presentation. 


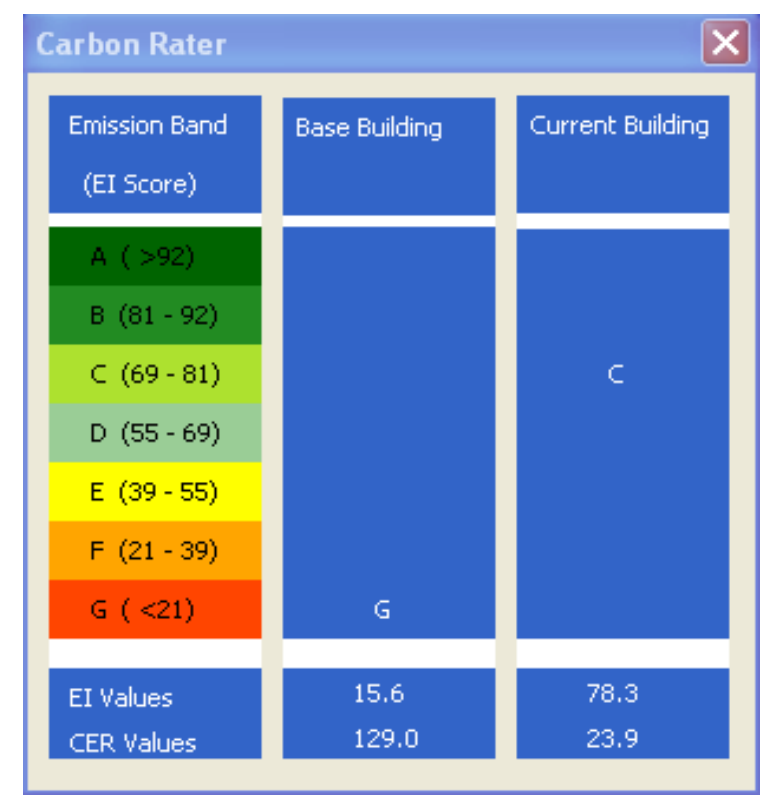

Figure 9: An EDEM Energy Performance

Certificate for the case described in Figure 8.

\subsection{Case study: national stock upgrade}

A digest of the 2002 Scottish House Condition Survey data has shown that the 2,278,000 dwellings in Scotland give rise to a total annual space heating demand of 14.5 TWh and $\mathrm{CO}_{2}$ emission of $5.5 \mathrm{MT}$ (domestic space heating accounts for $17 \%$ of the total Scottish energy demand). The entire national housing stock can be classified into 3 groups (or TCs) as listed in Table 1; the largest housing sector is contained within Group 1, which includes TCs associated with unimproved dwellings constructed prior to 1981. This grouping accounts for 11.1 TWh of annual space heating energy.

Table 1: Digest of Scottish dwellings.

\begin{tabular}{l}
\hline 1: high thermal mass, poor insulation, high air change rate \\
Number of dwellings: 1,594,600 \\
Average heating demand (kWh/m2.yr): 87 \\
\hline 2: standard insulation, high air change rate \\
Number of dwellings: 660,620 \\
Average heating demand (kWh/m2.yr): 47 \\
\hline 3: high insulation, standard air change rate \\
Number of dwellings: 22,780 \\
Average heating demand (kWh/m2.yr): 26 \\
\hline
\end{tabular}

Practical considerations dictate that any upgrading strategy should focus on low cost technologies initially to maximise the return on investment, and be phased over time thereafter to accommodate technical advances. Reducing ventilation and fabric heat loss are the most effective measures to improve dwelling thermal performance and these were assessed at the outset of the study. 
A preliminary EDEM analysis indicated that the most cost-effective upgrade strategy should be to target an appropriate sub-set of the Group 1 dwellings by improving their air tightness to standard (through the application of basic draught proofing) and applying lower cost insulation measures where appropriate to improve insulation to standard (e.g. cavity, internal or external wall insulation, double glazing and loft insulation). These actions would shift these properties to a Group 2 TC, with an associated saving of around $40 \mathrm{kWh} / \mathrm{m}^{2}$. Further analysis indicated that the remaining Group 1 dwellings along with the Group 2 dwellings (comprising original and previously upgraded Group 1 members) could be cost effectively improved to a Group 3 TC by more aggressively improving insulation and infiltration to achieve compliance with all elements of the 2002 UK regulations.

The implementation of the first phase of improvement measures was predicted to result in savings in the annual space heating energy demand of 4.7 TWh (or 33\% of the national energy demand). In the second phase of the programme, the annual space heating energy savings could be elevated to 7.36 TWh. Overall, a phased programme would reduce the annual space heating energy demand of the Scottish housing stock from 14.5 TWh to 7.14 TWh, i.e. a 52\% reduction of the space heating energy demand. Further details on the outcome of the project are given elsewhere (Clarke et al, 2004).

\subsection{Case study: regional housing upgrade}

A Local Authority housing stock comprising 7,876 dwellings was evaluated using EDEM to determine the impact on the carbon footprint of a range of upgrades (Tuohy et al 2006). The stock was decomposed into TCs using the Local Authority's available property data, while a range of possible upgrades were identified from the Energy Savings Trust's practical help publications (EST, 2007):

0 . current stock - no upgrades applied;

1. low cost fabric improvement - where there is a pitched roof and a suspended wooden floor then loft insulation is increased and the suspended timber floors insulated, all dwellings to have basic double glazing and be brought up to a tight infiltration standard;

2. major fabric upgrade - in addition to the low cost measures, flat roofs are upgraded to a U-value of $0.16 \mathrm{~W} / \mathrm{m}^{2} \mathrm{~K}$, cavity wall properties have insulation added to give a U-value of 0.35 , solid wall properties are improved to a U-value of 0.6 , and windows improved to a U-value of 1.5;

3. 2007 heating systems - gas, electricity and solid fuel heating systems are upgraded to meet the 2007 building regulation standards by the installation of a condensing boiler with instantaneous water heating, an air source heat pump with radiators and a wood boiler respectively;

4. Upgrades $1+2+3$;

5. Upgrade 4 plus solar hot water heating (delivering $920 \mathrm{kWh} / \mathrm{yr}$ useful energy applied to properties with an exposed roof);

6. Upgrade 5 plus local renewable energy generation $(650 \mathrm{kWh} / \mathrm{yr})$ in the form of either PV or small scale wind turbines at appropriate locations;

7. Upgrade 5 with gas boilers replaced with Stirling engine CHP.

8. Upgrade 5 with heating through individual or community wood boiler systems.

Figure 10 shows the impact of each upgrade option on the carbon footprint. These results show the current carbon footprint per dwelling to be 4.9 tonnes of $\mathrm{CO}_{2}$ per year, while 
future scenarios are presented with emissions below 1 tonne. Further details on the selected upgrade options and a breakdown of the study results by dwelling type are reported elsewhere (ibid).

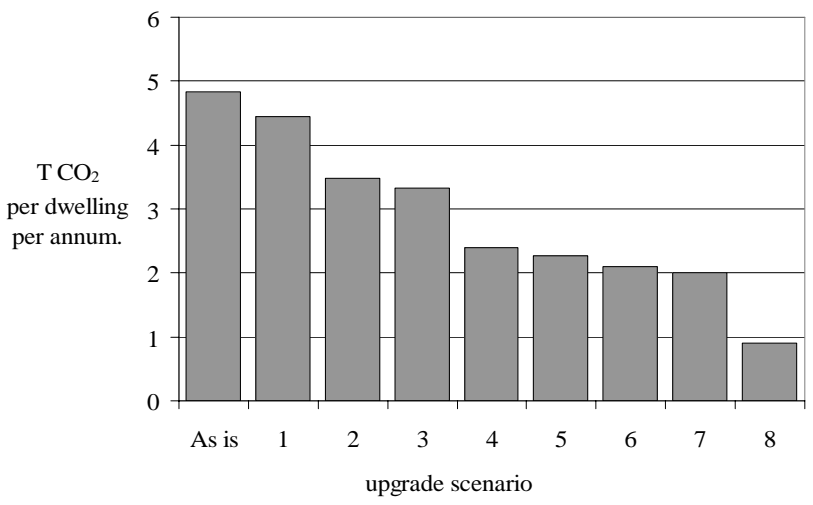

Figure 10: Impact of upgrade options on the carbon footprint of a Local Authority housing stock.

\subsection{Case study: dwelling energy labelling}

EDEM can be used to provide energy performance ratings. In this case, the Environmental Index (EI) and Energy Band (EB) are calculated from the generated energy demands in accordance with a standard UK method (BRE, 2005). Table 2 shows EDEM output when applied to an electrically heated 1980s dwelling, which had previously been upgraded with cavity wall insulation, double glazing and $200 \mathrm{~mm}$ of loft insulation. A number of further improvements were explored commencing with fabric improvements to 2002 standards, followed by alternative system replacement options: gas-fired condensing combination boiler; ground source heat pump; community biomass heating; community gas-fired combined heat and power; and a hybrid system comprising a condensing combination boiler, solar water heating and a PV panel producing $920 \mathrm{kWh}_{\mathrm{t}}$ and $650 \mathrm{kWh}_{\mathrm{e}}$ annually. From the results of Table 2, it can be seen that two upgrade options were able to raise the initial ' $D$ ' rating to 'A': upgraded fabric with either community biomass heating or community gas-fired combined heat and power.

\subsection{Case study: impact of grid electricity generation mix}

EDEM allows investigations across a range of system types, dwelling types and contexts (climates, behavior patterns, grid carbon intensity etc) to inform policy. One study analysed the 2050 scenarios proposed by the UK Carbon Trust's Buildings Market Transformation (BMT) project (Carbon Trust, 2008) in order to establish the impact of the electricity grid generation mix on technology performance. An assumption used in some scenarios is that while imported grid electricity has associated overall carbon emissions, electricity generated locally (CHP or renewable generation) displaces only the carbon fueled portion of grid generation plant. Multiple grid generation mixes were included in the EDEM study, including a current UK grid $\left(0.54 \mathrm{kgCO}_{2} / \mathrm{kWh}\right.$ overall, 0.73 $\mathrm{kgCO}_{2} / \mathrm{kWh}$ for the carbon fueled portion), a projected 2020 grid $\left(0.42 \mathrm{kgCO}_{2} / \mathrm{kWh}\right.$ and $0.57 \mathrm{kgCO}_{2} / \mathrm{kWh}$ respectively) and a projected 2050 grid $\left(0.3 \mathrm{kgCO}_{2} / \mathrm{kWh}\right.$ and 0.4 $\mathrm{kgCO}_{2} / \mathrm{kWh}$ respectively). The BMT scenarios include a range of gas-fired CHP systems 
(with various overall and electrical efficiencies) and electric heat pump options (with various Coefficient of Performance values).

Table 2: CO2 emission (kg/yr), Environmental Index (EI) and Energy Band (EB) for alternative upgrade options.

\begin{tabular}{lccc}
\hline Upgrade & Emission & EI & EB \\
\hline 0. As is & 3391 & 57 & $\mathrm{D}$ \\
\hline 1.2002 fabric & 2778 & 66 & $\mathrm{D}$ \\
\hline $2.1+$ gas condensing combi-boiler & 1679 & 81 & $\mathrm{~B}$ \\
\hline $3.1+$ ground source heat pump & 1515 & 83 & $\mathrm{~B}$ \\
\hline $4.1+$ community biomass heating & 817 & 93 & $\mathrm{~A}$ \\
\hline $5.1+$ community gas-fired CHP & 1000 & 98 & $\mathrm{~A}$ \\
\hline $6.2+$ PV + solar thermal & 1454 & 84 & $\mathrm{~B}$ \\
\hline
\end{tabular}

EDEM quantified the carbon performance of various technologies applied to dwellings with poor, average or 2002 standards of insulation/infiltration for each grid scenario. Figures 11 and 12 show the results for the 2020 and 2050 grids, while Figure 13 shows the carbon benefit relative to a condensing boiler for selected CHP and heat pump systems across the three grid scenarios. De-carbonizing the grid reduces the calculated carbon performance of CHP and other local generation technologies, while grid electricity fuelled systems such as heat pumps benefit from lower associated grid emissions.
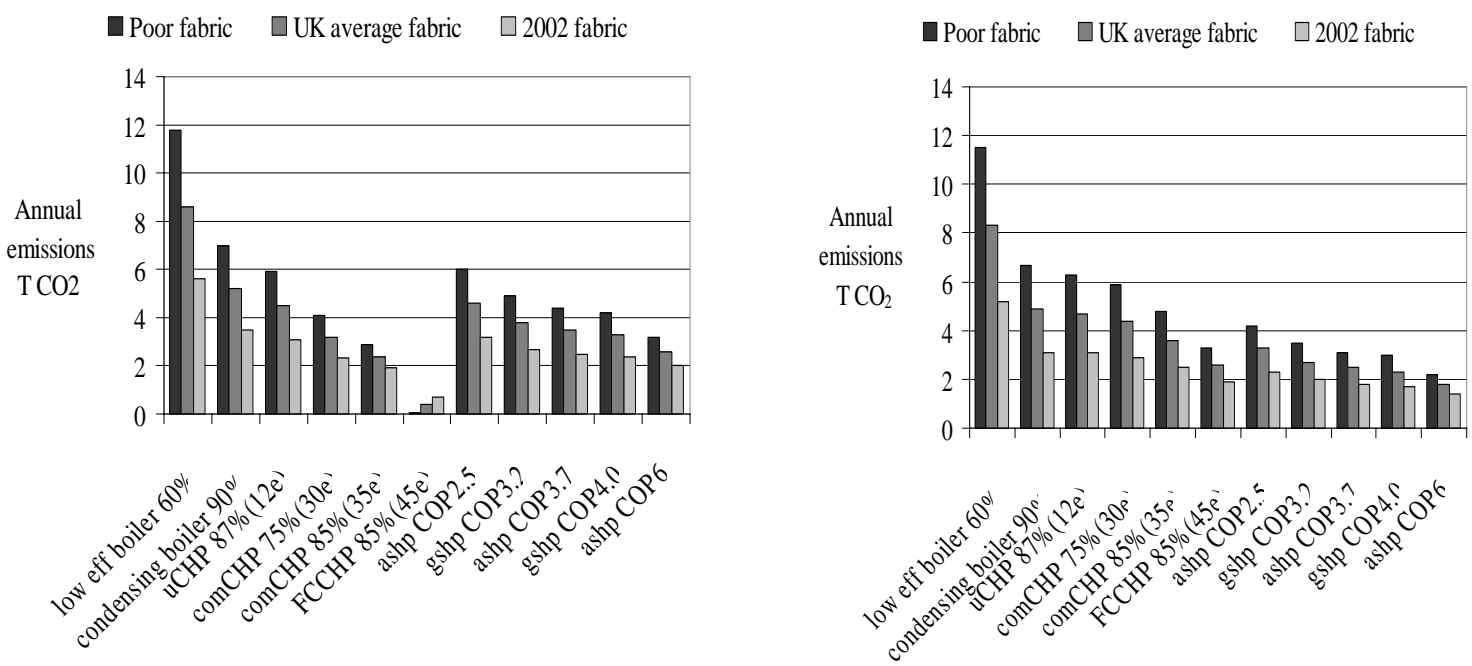

Figure 11: 2020 Grid - annual emissions associated with dwellings of poor, UK average and 2002 regulation insulation/infiltration and a range of heating systems including gas boilers, CHP (micro (u), community (com) and fuel cell (FC)) and heat pumps (air and ground source).
Figure 12: 2050 Grid - annual emissions associated with dwellings of poor, UK average and 2002 regulation insulation / infiltration and a range of heating systems including gas boilers, CHP (micro, community and fuel cell) and heat pumps (air and ground source). 


\subsection{Case study: financial appraisal of upgrade options}

EDEM can be used for financial appraisal in support of policy or building upgrade strategy. The BMT 2050 scenarios were analysed for both a medium feed-in tariff (locally generated electricity is exported to the grid at a tariff equal to half the electricity import price) and a high feed-in tariff (locally generated electricity is consumed locally or exported at a tariff equal to the import price). While more detailed financial analyses may be carried out, the project defined an upgrade as economic if the payback period was less than the expected lifetime (20 years for a technical system, 40 years for fabric upgrades and 30 years if combined). From the results (Figure 14) the upgrades applied to the poor dwelling were shown to be economic while the upgrades were marginal or uneconomic for a UK average dwelling except for the 2002 fabric upgrade, low cost/high efficiency heat pump or efficient CHP systems where there is a high feed-in tariff.

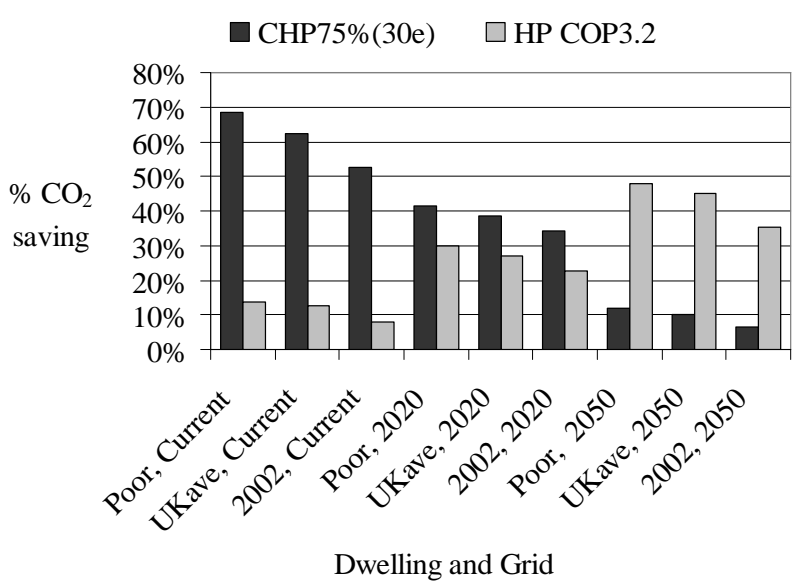

Poor fabric, $60 \%$ eff. boiler $\quad \square$ UK ave fabric, $76 \%$ eff. boiler
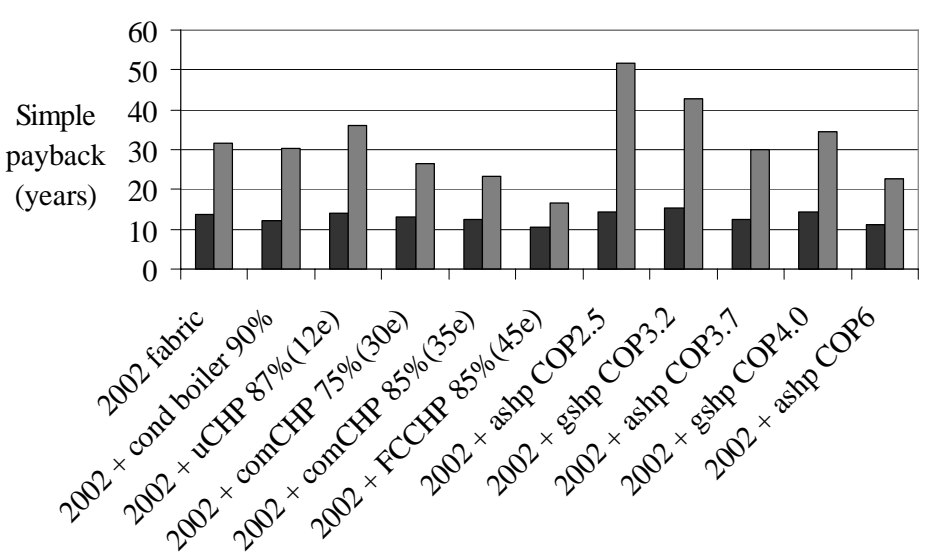

Figure 13: Current, 2020 and 2050 Grid scenarios calculated carbon savings (relative to a gas condensing boiler) for a gas CHP system (75\% overall efficiency, 30\% electrical, supplying $70 \%$ of demand) and a heat pump (COP of 3.2) applied to dwellings of Poor, UK average and 2002 insulation/infiltration.

Figure 14: Simple payback for upgrades applied either to a dwelling with poor insulation/infiltration and $60 \%$ efficient gas boiler or a dwelling with UK average insulation/infiltration and $76 \%$ efficient gas boiler where a high electricity price is associated with local electricity generation (high feed-in tariff). 


\subsection{Case study: financial appraisal of individual dwelling upgrade}

Specific measures applied to individual dwellings can be assessed using EDEM. For example (Table 3), a 3 bedroom mid terraced house built in 1929 with electric storage heating was upgraded with: ground floor insulation, external wall insulation, loft insulation, timber framed double glazing, low energy lighting, efficient A-rated appliances, ground source heat pump, controls and a solar water heater. The calculated cost of this upgrade package was $£ 13,492$ and the calculated fuel cost saving was estimated as $£ 1,773$ per year giving a simple payback of 7.6 years. This upgrade produced a calculated reduction in carbon footprint from 9.3 to 1.8 Tonnes of $\mathrm{CO}_{2}$ per year, i.e. a predicted saving of $80 \%$.

Table 3: Analysis of an upgrade package applied to an individual dwelling.

\begin{tabular}{|c|c|c|c|}
\hline & Original & Upgraded & Delta \\
\hline Heating kWh/m2 pa. & 204 & 25 & 179 \\
\hline Hot water kWh/m2 pa. & 36 & 8 & 28 \\
\hline Lights kWh/m2 pa. & 9 & 5 & 4.5 \\
\hline Appliances kWh/m2 pa. & 25 & 15 & 10 \\
\hline Total KWh/m2 pa. & 274 & 53 & 221 \\
\hline Running cost $£$ pa. & $£ 2,245$ & $£ 472$ & $£ 1,773$ \\
\hline Total T CO2 pa. & 9.26 & 1.78 & 7.48 \\
\hline EPC Rating & $\mathrm{F}$ & $\mathrm{B}$ & \\
\hline Capital cost $£$ & & & $£ 13,492$ \\
\hline Simple payback Years. & & & 7.6 \\
\hline
\end{tabular}

\section{Conclusions}

Building performance simulation is now being used in support of policy development. The goal is to provide decision-makers with the means to compare energy supply and demand, at a local or regional level, in terms of the match at present or as it might exist under some future scenario. By enabling informed decisions, opportunities for costeffective upgrades and the exploitation of renewable energy systems at local (autonomous) and strategic (grid connected) levels can be fully explored. The approach allows the accuracy and applicability advantages of dynamic simulation to be made accessible to those who are concerned with the management and adaptation of large estates. Typically, an energy simulation program is applied to a set of building models that represent the spectrum of upgrade possibilities and the output predictions embedded in another, easy to use policy support tool. In this paper, the use of the approach has been demonstrated at a number of levels from national stock to individual dwellings. The methodology is general and can be applied to any building stock and climate region.

\section{Acknowledgements}

The authors thank Dr Linda Sheridan and Mr Gavin Peart of the Scottish Building Standards Agency for supporting EDEM development. Recent developments of EDEM were performed within the Building Market Transformation project sponsored by the UK Carbon Trust: particular thanks to Sabeeta Ghauri of ESRU for her inputs to the EDEM interface. 


\section{References}

Bamborough K, Brown A, Clarke J A, Evans M, Grant A D, Lindsay M and Morgan J (1996), 'Integration of Renewable Energies in European Regions', Final Report to the European Commission for Project RENA-CT94-0064.

Bartholomew D and Robinson D (Eds) (1998), 'Building Energy and Environmental Modelling: Applications Manual 11’, CIBSE, London, ISBN 0-900953-85-3.

BRE (2005), 'Standard Assessment Procedure for Energy Rating of Dwellings', Building Research Establishment Publication.

Carbon Trust (2008), http://www.carbontrust.co.uk/technology/carbonvision/buildings.htm.

CIBSE, (2006), ‘Environmental Design’, CIBSE Guide A, ISBN 0-900953-96-9.

Clarke J A, Evans M S, Grant A D, Kelly N (1997), 'Simulation Tools for the Exploitation of Renewable Energy in the Built Environment: The EnTrak System' Proc. Building Simulation '97, Prague.

Clarke J A, Johnstone C M, Kondratenko I, Lever M, McElroy L B, Prazeres L, Strachan P A, McKenzie F and Peart G (2004), 'Using simulation to formulate domestic sector upgrading strategies for Scotland’, Energy and Buildings, 36, pp759-70.

Crawley D (2007), 'Creating weather files for climate change and urbanisation impacts analysis', Proc. Building Simulation '07.

Crawley D (2007a), 'Estimating the effects of climate change and urbanisation on building performance', Proc. Building Simulation '07.

Crawley D, Hand J.W, Kummert M, Griffith B.T (2008), 'Contrasting the capabilities of building energy performance simulation programs', Building and Environment, 43, pp661-673.

de la Rue du Can and Price L (2008), 'Sectoral trends in global energy use and greenhouse gas emissions’, Energy Policy, 36, pp1386-1403.

EC (2002), 'On the Energy Performance of Buildings', Directive 2002/91/EC of the European Parliament.

EDEM (2007), www.esru.strath.ac.uk/Programs/EDEM.htm.

ESP-r (2007), www.esru.strath.ac.uk/Programs/ESP-r.htm.

EST (2007), 'UK Government Energy Efficiency Best Practice Programme, www.est.org.uk/bestpractice. 
Hashimoto S, Yamaguchi Y, Shimoda Y, MizunoM (2007), 'Simulation model for multipurpose evaluation of urban energy system', Proc. Building Simulation '07.

Heiple S and Sailor D J (2008), 'Using building energy simulation and geospatial modeling techniques to determine high resolution building sector energy consumption profiles', Energy and Buildings, 40, pp1426-1436.

Hu J, Yang C and Yu C (2007), 'Building energy analysis and simulation of Changsha area', Proc. Building Simulation '07.

ISO (2007), 'Energy Performance of Buildings - Calculation of Energy Use for Space Heating and Cooling', ISO Standard 13790, Geneva.

Jones P J, Lannon S and Williams J (2001) 'Modelling Building Energy Use at the Urban Scale', Proc. Building Simulation ’01, Rio de Janeiro.

Kim J and Clarke J A (2004), 'The EnTrak System: Supporting Energy Action Planning via the Internet', Proc. CTBUH '04, Seoul.

Li Q, Jones P and Lannon S (2007), 'Planning sustainable in Chinese cities: dwelling types as a means to accessing potential improvements in energy efficiency', Proc. Building Simulation '07.

MTP (2006), UK Market Transformation Project, www.mtprog.com.

NHER (2008), NHER: Software for Existing Dwellings, NHER Surveyor, www.nher.co.uk/pages/software/existing.php.

Scottish Homes (2002), Scottish House Condition Survey 2002, www.shcs.gov.uk.

Shorrock L D and Utley J I (2003), 'Domestic Fact File', BRE Publications, ISBN 1 860816231.

Staunton G (2008), 'The Carbon Vision Buildings Programme', CIBSE/ASHRAE Conference: Sustainability - Niche to Norm, 29-30 April 2008, Gateshead.

Taniguchi A, Shimoda Y, Asahi T, Yamaguchi Y, Mizuno M (2007), 'Effectiveness of energy conservation measures in residential sectors of Japanese cities', Proc. Building Simulation '07.

Tuohy P G, Strachan P A and Marnie A (2006), 'Carbon and Energy Performance of Housing: A Model and Toolset for Policy Development Applied to a Local Authority Housing Stock’, Proc. Eurosun ‘06, Glasgow.

Urge-Vorsatz D and Novikova A (2008), 'Potentials and costs of carbon dioxide mitigation in the world's buildings', Energy Policy, 36, pp642-661. 
Xie D, Zhang G and Zhou J (2007), 'Analysis of building energy efficiency strategies for the hot summer and cold winter zone in China', Proc. Building Simulation '07.

Yamaguchi Y, Shimoda Y, Mizuno M (2003), 'Development of district energy system simulation model based on detailed energy demand', Proc. Building Simulation '03. 